\title{
Pneumatosis Cystoides Intestinalis: Rare Cause of Pneumoperitoneum. Case Report and Review of Literature
}

Mehdi Bourakkadi Idrissi ${ }^{*}$, Faouzi Laytimi ${ }^{1}$, Mohamed Fdil ${ }^{1}$, Ouadii Mouaqit ${ }^{1}$, Abdelmalek Oussaden ${ }^{1}$, Khalid Ait Taleb $^{1}$, El Bachir Benjelloun ${ }^{1}$, Hicham El Bouhadoutti ${ }^{1}$

${ }^{1}$ Faculty of Medicine and Pharmacy, Sidi Mohamed Ben Abdellah University of Fez, Morocco

Visceral Surgery Department A, CHU Hassan II, Fez, Morocco

DOI: $\underline{10.36347 / \mathrm{sasjs} .2021 . \mathrm{v} 07 \mathrm{i} 04.012}$

| Received: 15.03.2021 | Accepted: 19.04.2021 | Published: 24.04.2021

*Corresponding author: Mehdi Bourakkadi Idrissi

\section{Abstract}

Pneumatosis cystoides intestinalis (PCI) is low incidence disease, with atypical symptoms and imaging manifestations making it hard to diagnose. It is characterized by the presence of gas in the mucosa or submucosa of the digestive tract [1]. Its pathogenesis remains unclear; however, three theories have been accepted: the mechanical theory [2], the pulmonary theory [1] and the bacterial theory [3, 4]. Pneumoperitoneum caused by ruptured serosal cyst(s) of PCI is a rare but "benign" entity in the emergency setting that can be managed conservatively [5]. Here we present a case of 50-year-old male admitted to the emergency department with acute upper abdominal pain, with signs of bowel obstruction. CT scan showed indirect signs of mesenteric ischemia with an intraperitoneal free air. Patient was admitted to the operating room on the same day, and the examination revealed multiple cysts on the subserous of the small intestine. No intestinal perforation was diagnosed thus we opted for a therapeutic abstention. PCI's prognosis is optimistic. Therefore, clinicians should increase their awareness of PCI to avoid unnecessary misdiagnosis. Surgery is only recommended when complications are suspected.

Keywords: Pneumatosis Cystoides, (PCI), mechanical theory, pulmonary theory.

Copyright $\left({ }_{0} 2021\right.$ The Author(s): This is an open-access article distributed under the terms of the Creative Commons Attribution 4.0 International License (CC BY-NC 4.0) which permits unrestricted use, distribution, and reproduction in any medium for non-commercial use provided the original author and source are credited.

\section{INTRODUCTION}

Pneumatosis cystoides intestinalis (PCI) is a low incidence disease, with atypical symptoms and imaging manifestations making it hard to diagnose. It is characterized by the presence of gas in the mucosa or submucosa of the digestive tract [1].

PCI lesions are mainly located in the colon $(46 \%)$ and small intestine $(27 \%)$, followed by the large and small intestine (7\%) and stomach (5\%) [6].

As a consequence of atypical clinical manifestations and endoscopic findings, it is not rare to misdiagnose PCI as intestinal polyps, tumors, or other inflammatory bowel diseases.

Opposed to the treatment of the above diseases, PCI treatment is effective and convenient, and the prognosis remains optimistic. Therefore, clinicians should increase their awareness of PCI to avoid unnecessary misdiagnosis [1].
Pneumoperitoneum caused by ruptured serosal cyst(s) of PCI is a rare but 'benign' 'entity in the emergency setting that can be managed conservatively [5].

\section{CASE PRESENTATION}

Patient is a 50-year-old Moroccan male, with a medical history of a surgery 9 years prior for a perforated duodenal ulcer, and another undocumented surgery for bowel obstruction. The patient was admitted to the emergency department with signs of bowel obstruction yet again, with acute upper abdominal pain. Abdominal examination revealed a scar of a midline laparotomy. It also found tenderness in the upper abdomen.

An injected CT-Scan was performed right away, discovering gas in the portal vein [Figure1], alongside gas in the intestinal wall [Figure2] and pneumoperitoneum [Figure1]. All of which were considered to be indirect signs of mesenteric ischemia 


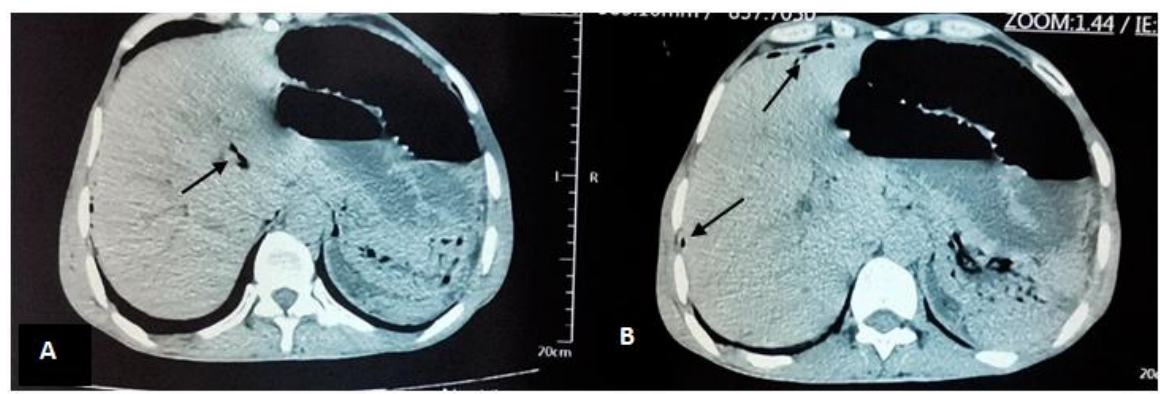

Fig-1: CT Scan images : A. Portal vein gas B. Pneumoperitoneum

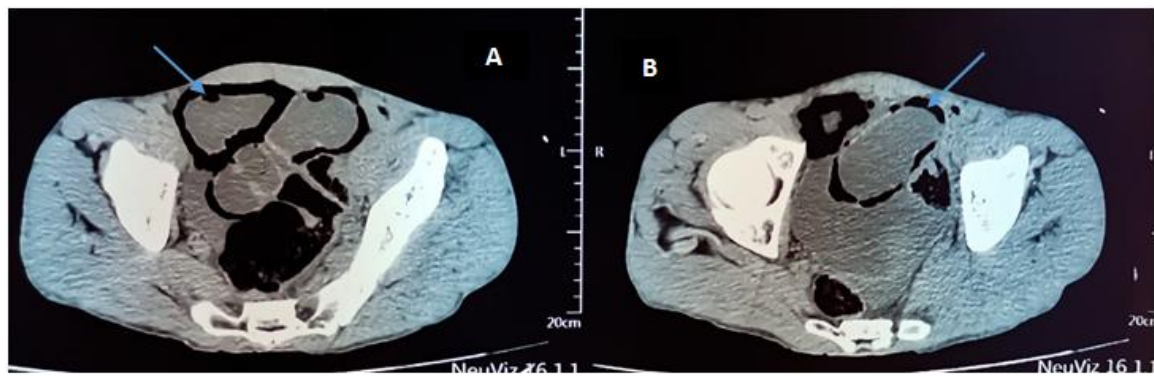

Fig-2: Gas in the intestinal wall

After the routine work up and proper resuscitation, laparotomy was performed. Widespread variable sized serosal intestinal air cysts were seen at the first look involving long segment of jejunum and ileum. One of which was ruptured, hence explaining the free air in the peritoneum. No signs of bowel ischemia were found, nor any signs of perforation [Figure3]. Therapeutic abstention was decided.

The patient passed very smooth postoperative course with no complication, and was discharged after five days.

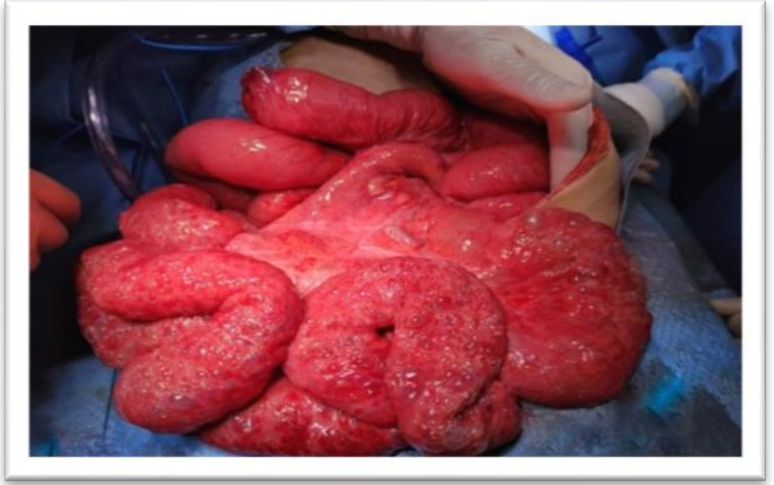

Fig-3: Widespread variable sized serosal intestinal air cysts, aspect of PCI

\section{DISCUSSION}

Pneumatosis cystoids intestinalis (PCI) is a low-incidence disease that confuses many doctors. Many factors play a role in its pathogenesis, such as inflammatory bowel diseases, extra-gastrointestinal diseases and chronic obstructive pulmonary disease.
PCI can be divided into primary (15\%) and secondary $(85 \%)$ types $[1,7]$. The secondary form occurs as a consequence to diseases like the ones we previously cited, but can also happen secondary to an abdominal external injury or surgery.

In the literature we found three hypotheses behind the development of PCI. The first theory is the mechanical theory [2]. Mechanical damage secondary to an increase of intraluminal pressures causes a mucosal rupture of the intestinal wall, thus allowing the migration of gas from the gastrointestinal cavity through the intestinal wall.

Second theory is the pulmonary theory [1]. Alveolar rupture, as a consequence of chronic lung diseases such as asthma, or chronic obstructive pulmonary disease, induces mediastinal emphysema and a release of gas alongside the aorta and its mesenteric branches going into the intestinal wall. And the last theory is the bacterial theory [3, 4] where aerogenic bacteria are believed to produce gas in the intestinal wall penetrating the intestinal mucosal barrier.

Primary PCI does not have any specific clinical manifestation. Symptoms may vary from abdominal pain $(59 \%)$, to diarrhea $(53 \%)$, nausea and vomiting $(14 \%)$, mucus in stool $(12 \%)$, or hematochezia (12\%) [1]. about $3 \%$ of the patients with PCI complained from complications, including pneumoperitoneum, volvulus, intestinal obstruction, and intestinal ischemia. Which is the case of our patient $[8,9]$ ? Serious complications may alter the decisionmaking process for the therapeutic schedule. 
Mehdi Bourakkadi Idrissi et al., SAS J Surg, Apr, 2021; 7(4): 207-209

Treatment includes observation, oxygen therapy, endoscopic treatment, and surgery. The treatment should be tailored to the clinical symptoms and endoscopic manifestations to avoid unnecessary surgery. If no serious complications occur, the prognosis is optimistic.

The majority of researchers consider PCI as a benign disease which only requires conservative treatments: observation; oxygen or antibiotics were among the suggested treatments. Kensuke Nakatani et al. reported that hyperbaric oxygen therapy is the preferred method [10].

Antibiotics including metronidazole and quinolones can inhibit intestinal bacterial infection. Endoscopic fine needle aspiration contributes to both the diagnosis and treatment of PCI, by puncturing the cyst to exhaust gas $[11,12]$.

In order to better manage patients with severe PCI, all patients should be divided into three groups: patients requiring surgery, patients who don't require surgery, and patients with benign intestinal emphysema. The primary operative indications are considered if the patient meets any of the following criteria: obstructive symptoms, WBC > $12 \mathrm{c} / \mathrm{mm} 3$ or CT findings of portal vein gas, due to the high mortality rate associated with this condition. Which is the case of our patient who presented both obstructive symptoms and portal vein gas in the CT scan $[13,14]$.

\section{CONCLUSION}

To conclude, PCI is a not as uncommon disease as it is believed to be, that still confuses many doctors, with still unclear etiology and pathogenesis. Pneumatosis cystoides intestinalis may be associated with bowel ischemia, perforation, and a high mortality rate. As a result, many authorities advocate an aggressive surgical approach in those patients [4]. PCI's prognosis is optimistic. Therefore, clinicians should increase their awareness of PCI to avoid unnecessary misdiagnosis. Surgery is only recommended when complications are suspected.

\section{REFERENCES}

1. Wu L-L, Yang Y-S, Dou Y, Liu Q-S. A systemic analysis of pneumatosis cystoids intestinalis. World J Gastroenterol. 2013;19(August (30)):4973-8.

2. Khail PN, Huber-Wagner S, Ladurner R, Kleespies A, Siebeck M, Mutschler W, Halfeldt K, Kanz KG. Natural history, clinical pattern, and surgical consideration of pneumatosis interstialis. Eur $\mathrm{J}$ Med Res. 2009;14(6):231-9.

3. Boerner RM, Frie DB, Warshauer DM, Isaacs K. Pneumatosis intestinalis. Two case reports and a retrospective review of literature from 1985 to 1995. Dig Dis Sci. 1996;41(11):2272-85
4. Gillon J, Tadesse K, Logan RF, Holt S, Sircus W. Breath hydrogen in pneumatosis cystoides intestinalis. Gut. 1979;20:1008-11.

5. Wada K, Takeuchi N, Emori M. Two cases of pneumatosiscystoides intestinalis with intraperitoneal free air. Gastroen-terol Res. 2017; 10:208-11.

6. Morris MS, Gee AC, Cho SD, Limbaugh K, Underwood S, Ham B, Schreiber MA. Management and outcome of pneumatosis intestinalis. Am J Surg. 2008;195(5):679-82

7. Greenstein AJ, Nguyen SQ, Berlin A, Corona J, Lee J, Wong E, Factor SH, Divino CM. Pneumatosis intestinalis in adults: managements, surgical indivations, and risk factors for mortality. J Gastrointest Surg. 2007;11(10):1268-74.

8. Ogul H, Pirimoglu B, Kisaoglu A, Karaca L, Havan N, Ozogul B, Kantarci M. Pneumatosis cystoides intestinalis: an unusual cause of intestinal ischemia and pneumoperitoneum. Int Surg. 2015;100(2):221-4.

9. Du Bose JJ, Lissauer M, Maung AA, Piper GL, O'Callaghan TA, Luo-Owen X, Inaba K, Okoye O, Shestopalov A, Fielder WD, Ferrada P, Wilson A, Channel J, Moore FO, Paul DB, Johnson S. Pneumatosis intestinalis predictive evaluation study (PIPES):a multicenter epidemiologic study of the eastern association for the surgery of trauma. J Trauma Acute Care Surg. 2013;75(1):15-23.

10. Nakatani K, Kato T, Okada S, Matsumoto R, Nishida K, Komuro H, Suganuma T. Successful treatment with hyperbaric oxygen therapy for pneumatosis cystoides intestinalis as a complication of granulomatosis with polyangiitis: a case report. J Med Case Rep. 2017;11:263.

11. Cyrany J, Kopácová M, Rejchrt S, Hornychová H, Tomsová M, Tycová V, Ryska A, Bures J. Puncture and cytology - sufficient for endoscopic diagnosis of pneumatosis cystoides intestinalis? Endoscopy. 2009;41(Suppl 2):E127-8.

12. Kim YG, Kim KJ, Noh SH, Yang DH, Jung KW, Ye BD, Byeon JS, Myung SJ, Yang SK. Clear water filling and puncture: sufficient for endoscopic diagnosis of pneumatosis cystoides intestinalis? (with video). Gastrointest Endosc. 2011;74(5):1170-1.

13. Theisen J, Juhnke P, Stein HJ. Pneumatosis cystoides intestinalis coli. Surg Endosc. 2003; 17(1):157-158.

14. Greenstein AJ, Nguyen SQ, Berlin A, Corona J, Lee J, Wong E, Factor SH, Divino CM. Pneumatosis intestinalis in adults: management, surgical indications, and risk factors for mortality. Journal of Gastrointestinal Surgery. 2007 Oct 1;11(10):1268-74.

15. Tchabo NE, Grobmyer SR, Jarnagin WR, Chi DS: Conservative management of pneumatosis intestinalis. Gynecol Oncol; 2005. 